\title{
The End User is Not Fully Benefiting with the Knowledge of Physicians: A Dilemma and Disparity in Diabetes
}

\author{
Abdul Sattar Khan \\ Family and Community Medicine Department, Medical Faculty, King Faisal University, Saudi Arabia
}

*Corresponding author: Abdul Sattar Khan, Head and Assistant Professor, Family and Community Medicine Department, Medical Faculty, King Faisal University, Saudi Arabia, Tel: 00966508973724; E-mail: drsattarkhan@gmail.com

Received date: Oct 16, 2015; Accepted date: Dec 26, 2015; Published date: Jan 1, 2016

Copyright: (c) 2016 Khan AS. This is an open-access article distributed under the terms of the Creative Commons Attribution License, which permits unrestricted use, distribution, and reproduction in any medium, provided the original author and source are credited.

\section{Commentary}

Since two decades after discovering of Diabetes Mellitus too many developments been appreciated in every part from diagnosis till management [1]. Furthermore, during this period there have been many terms coined like "concordance" [2], Shared Decision Making (SDM) [3] and patient as an "expert" [4] for increasing compliance. However, there are several reasons i.e. more diagnostic focus, awareness, epidemiological transition and life style etc [5], we witness of an uprising of diabetes mellitus in the whole world, whereas Middle East situation is worst as it is forecast to grow to 67.9 million by 2035 [6]. Yet, perceptibility the patients are not compliant enough to manage their diabetes in many parts of the world [7].

The issue of non-compliance is a complex subject and might have countless other reasons in the world including Arab society [7-9]. However, the author feels strongly that the current Arab society feels that they find themselves running out of time. Since the physicians are also part of this hurry society thus unable to transfer the necessary knowledge of management to end-user $[9,10]$. And there is still a huge gap between communication in between physicians and patients [10]. Unquestionably, it is also supported and emphasized by the other studies that physician interruption time is very short in consultation and it varies from 18 seconds [11] to 23.1 seconds [12].

Indeed, the involvement of patients in management decisions [5] is emphasized upon and there are several models considered even for management of diabetes too [10]. However, the patients often say that their consultations are too short and that doctors do not use the time well $[10,11]$. The patients are also sometime in a hurry [11-14] and don't want to listen the physicians. Still, theoretically both parties are in a state of gusts, which would nurture it exponentially and could be explained with the evidence by a mathematical exponential function [15].

Sometimes this state of double effect causes burnout syndrome [14] among physicians. Though in current life style, it is understandable that it is not an easy task to deal with long working hours of a daily bases, unrealistic patients' demands, received a question about own abilities by the patients etc. Which are some of the dimensions of burnout syndrome [16], however, author believes it is mainly because of mismanagement of time and reflects not only on their lives, but also depicted in their practices [12]. Hence, it raises two issues; the communication gap as well as the time management.

Though competency based curriculum addresses these issues to some extend, however, utterly we need to concentrate more on the interaction lane. Still the medical educationists are in debate about the weightage of these soft skills in the undergraduate curriculum, but the policy makers appear more reluctant to give due emphasis on these skills. Nevertheless, most of the countries in Middle East region adapted the curriculum from western world yet, due to the cultural differences like male and female segregation in medical education, female patients preference to see the female physicians and patients don't appreciate to be part in decision making about management of the disease; the impression appears to be worst and still reveals a massive gap between them and further part of the world as regard to the training of these skills. Therefore, it should be mandatory that medical students in this region should have invariably longitudinal communication skills curriculum from first year till internship.

\section{References}

1. World Health Organization Media Center. Diabetes Fact Sheet.

2. Centers for Disease Prevention. Press release: Number of Americans with Diabetes Projected to Double or Triple by 2050.

3. Badran, Mohammad, Laher I (2012) "Type II diabetes mellitus in Arabicspeaking countries." International journal of endocrinology Article ID 902873.

4. Chatterjee JS (2006) From compliance to concordance in diabetes. J Med Ethics 32: 507-510.

5. Charles, Cathy, Amiram Gafni, and Tim Whelan. (1997) "Shared decision-making in the medical encounter: what does it mean?(or it takes at least two to tango)." Social science \& Medicine 44: 681-692.

6. Bodenheimer T, Lorig K, Holman H, Grumbach K (2002) Patient selfmanagement of chronic disease in primary care. JAMA 288: 2469-2475.

7. Hernández-Ronquillo L, Téllez-Zenteno JF, Garduño-Espinosa J, González-Acevez E (2003) Factors associated with therapy noncompliance in type-2 diabetes patients. Salud Publica Mex 45: 191-197.

8. Al-Qasem A, Smith F, Clifford S (2011) Adherence to medication among chronic patients in Middle Eastern countries: review of studies. East Mediterr Health J 17: 356-363.

9. Khan AR, Al-Abdul Lateef $\mathrm{ZN}, \mathrm{Al}$ Aithan MA, Bu-Khamseen MA, Ibrahim IA, et al. (2012) Factors contributing to non-compliance among diabetics attending primary health centers in the Al Hasa district of Saudi Arabia. Journal of Family and Community Medicine 19: 26-32.

10. Khan A S (2013) Do Family Physicians have to share decision making with their patients? Euras J Fam Med 2: 37-42.

11. Marvel MK, Epstein RM, Flowers K, Beckman HB (1999) Soliciting the patient's agenda: have we improved? JAMA 281: 283-287.

12. Beckman HB, Frankel RM (1984) The effect of physician behavior on the collection of data. Ann Intern Med 101: 692-696.

13. Butler J, Calnan M (1987) Too many patients? A study of economy of time and standards of care in general practice. Aldestrot, Avebury. Lavoisier.fr.

14. Deveugele $M$, Derese A, van den Brink-Muinen A, Bensing J, De Maeseneer J (2002) Consultation length in general practice: cross sectional study in six European countries. BMJ 325: 472.

15. Lay DI, Asmar NH (2006) Brief calculus and its applications. 11th ed. Prentice-Hall. 
Citation: Abdul Sattar (2016) The End User is Not Fully Benefiting with the Knowledge of Physicians: A Dilemma and Disparity in Diabetes. J Pat Care 2: 106. doi:10.4172/2573-4598.1000106

Page 2 of 2

16. Dusmesnil H, Serre BS, Régi JC, Leopold Y, Verger P (2009) Professional burn-out of general practitioners in urban areas: prevalence and determinants. Sante Publique 21:355-364. 